\section{Commentary: The next chapter in donor heart preservation: Modulation of preservation biology by targeted molecular therapies}

\author{
Ienglam Lei, $\mathrm{PhD}$, and Paul C. Tang, $\mathrm{MD}, \mathrm{PhD}$
}

Existing donor heart preservation technology is based on the concepts of lowering metabolic demands through hypothermia and mechanical arrest as well as preventing tissue swelling and providing energy substrates. ${ }^{1}$ These concepts were developed several decades ago by distinguished pioneers in the field, including Gerald Buckberg, ${ }^{2}$ Folkert Belzer, ${ }^{3}$ and James Southard. ${ }^{3}$ However, the breakneck speed of advances in diagnostic and therapeutic molecular technology offers new opportunities to build on existing knowledge. Furthermore, expanding donor pools to the donations after circulatory death (DCD) population ${ }^{4}$ and the use of normothermic donor heart perfusion has introduced new challenges.

Quader and colleagues ${ }^{5}$ show that pharmacologic inhibition of the inflammasome can drastically improve the systolic and diastolic function of DCD hearts following transplantation. This was associated with a decrease in apoptosis-associated speck-like protein containing a caspase recruiting domain expression, which is a key inflammasome component. The beneficial effects of inflammasome inhibition in DCD hearts was previously confirmed in a mice NLR family pyrin domain containing 3 knockout model. ${ }^{6}$ Although the current study focuses on left ventricle preservation, it would be of interest to determine the effect of inflammasome inhibition on the right side of the heart. There may be differences given the

\footnotetext{
From the Department of Cardiac Surgery, University of Michigan, Ann Arbor, Mich. Disclosures: The authors reported no conflicts of interest.

The Journal policy requires editors and reviewers to disclose conflicts of interest and to decline handling or reviewing manuscripts for which they may have a conflict of interest. The editors and reviewers of this article have no conflicts of interest.

Received for publication June 14, 2021; revisions received June 14, 2021; accepted for publication June 28, 2021; available ahead of print July 1, 2021.

Address for reprints: Paul C. Tang, MD, PhD, Department of Cardiac Surgery,

University of Michigan, 5158 Cardiovascular Center, SPC 5864, 1500 E. Medical

Center Dr., Ann Arbor, MI 48109-5864 (E-mail: tangpaul@med.umich.edu).

JTCVS Techniques 2021;9:95-6

2666-2507

Copyright (C) 2021 The Author(s). Published by Elsevier Inc. on behalf of The American Association for Thoracic Surgery. This is an open access article under the CC BY-NC-ND license (http://creativecommons.org/licenses/by-nc-nd/4.0/). https://doi.org/10.1016/j.xjtc.2021.06.037
}
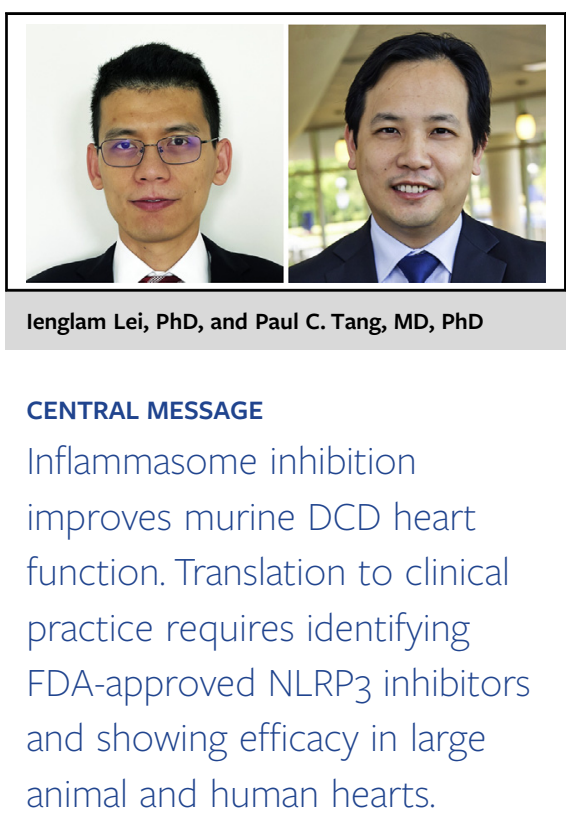

distinct embryonic origins of the left- and right-side chambers being derived from the primary and secondary heart fields, respectively. ${ }^{7}$ With these promising results, further confirmatory studies are needed in large animal (eg, pig) and/or human hearts to account for the diversity of responses in less inbred large animal or human populations. ${ }^{8}$ This will greatly facilitate the translation of proof-of-concept laboratory findings to the clinical setting.

Whereas the use of NLR family pyrin domain containing 3 inhibitor 16773-34-0 was impressively efficacious for improving DCD heart function, translation of this therapy into clinical practice needs to go through an arduous process of Food and Drug Administration (FDA) evaluation and approval requiring significant financial support. Although this is ultimately worthwhile, another strategy would be to identify FDA approved inflammasome inhibitors that can be repurposed for donor heart preservation. Indeed, pharmaceutical companies are already targeting inflammasome inhibitors for drug development. ${ }^{9}$ The translational science insights into cardiac preservation from investigations such as the current study are critical for timely utilization of novel FDA-approved pharmacologic agents.

This article from Quader and colleagues ${ }^{5}$ demonstrates the important role of the inflammasome activation in the DCD setting. Inflammasomes also likely have a role in a deceased brain death donation, after brain death, but this remains to confirmed in future studies. Current clinical DCD logistics involve cardioplegic arrest of the donor heart with subsequent mechanical normothermic perfusion ex vivo or in vivo using regional perfusion techniques. ${ }^{10}$ The heart is 
then assessed and/or transported for a variable time and then rearrested for implant into the recipient. Future experimental model will likely benefit from modeling this process because the duration of normothermic perfusion, ex vivo versus in vivo perfusion, and the influence of 2 cold cardioplegic arrest episodes all likely influence transplanted graft function. Understanding the biology of each of these components will be important for optimizing cardiac DCD.

\section{References}

1. Minasian SM, Galagudza MM, Dmitriev YV, Karpov AA, Vlasov TD. Preservation of the donor heart: from basic science to clinical studies. Interact Cardiovasc Thorac Surg. 2015;20:510-9.

2. Rosenkranz ER, Buckberg GD. Myocardial protection during surgical coronary reperfusion. J Am Coll Cardiol. 1983;1:1235-46.

3. Southard JH, Belzer FO. Organ preservation. Annu Rev Med. 1995;46:235-47.
4. Chew HC, Macdonald PS, Dhital KK. The donor heart and organ perfusion technology. J Thorac Dis. 2019;11:S938-45.

5. Quader M, Wickramaratne N, Toldo S. Improving circulatory death donor heart function: a novel approach. J Thorac Cardiovasc Surg Tech. 2021;9: 89-92.

6. Quader M, Mezzaroma E, Kenning K, Toldo S. Targeting the NLRP3 inflammasome to reduce warm ischemic injury in donation after circulatory death heart. Clin Transplant. 2020;34:e14044.

7. Kelly RG, Buckingham ME, Moorman AF. Heart fields and cardiac morphogenesis. Cold Spring Harb Perspect Med. 2014;4.

8. Houser SR, Margulies KB, Murphy AM, Spinale FG, Francis GS, Prabhu SD, et al. Animal models of heart failure: a scientific statement from the American Heart Association. Circ Res. 2012;111:131-50.

9. Corcoran SE, Halai R, Cooper MA. Pharmacological inhibition of the nod-like receptor family pyrin domain containing 3 inflammasome with MCC950. Pharmacol Rev. 2021;73:968-1000.

10. Ribeiro RVP, Alvarez JS, Yu F, Paradiso E, Adamson MB, Maria Ruggeri G, et al. Hearts donated after circulatory death and reconditioned using normothermic regional perfusion can be successfully transplanted following an extended period of static storage. Circ Heart Fail. 2019;12:e05364. 